\title{
Relação entre medidas de refletância e área foliar sadia, severidade da ferrugem asiática e produtividade da cultura da soja
}

\author{
Relationships between measures of reflectance and health leaf area, \\ soybean rust severity and soybean yield
}

Lucimara Junko Koga ${ }^{1}$; Marcelo Giovanetti Canteri ${ }^{2 *}$; Cláudia Vieira Godoy ${ }^{3}$

Resumo

O objetivo do trabalho foi verificar se as medidas de refletância detectavam variações na área foliar sadia a fim de serem utilizadas como parâmetros para estimar danos na produção decorrentes da ferrugem asiática, bem como determinar a influência da doença na eficiência fotossintética das plantas em condições de campo. O experimento foi conduzido na área experimental pertencente à Embrapa Soja, no município de Londrina, PR, utilizou-se a cultivar de soja BRS 154. O delineamento experimental utilizado foi de blocos ao acaso, com oito tratamentos (diferentes estádios de início da aplicação do fungicida) com quatro repetições $\mathrm{O}$ produto utilizado foi azoxistrobin + ciproconazole $(60+24 \mathrm{~g}$ i.a./ha) + óleo mineral $(0,5 \%)$. As leituras de refletância foram feitas em oito comprimentos de onda, de 460 a $810 \mathrm{~nm}$, em intervalos de $50 \mathrm{~nm}$. Calculou-se o Índice Vegetativo de Diferença Normalizada (NDVI), onde NDVI=(810$660) /(810+660)$. A produção apresentou incremento linear $(\mathrm{P}<0,01)$ com a Duração da Área Foliar Sadia (HAD) ( $\mathrm{r}^{2}=37,7 \%$ ), com a Absorção da Radiação Solar pela Área Foliar Sadia (HAA) $\left(\mathrm{r}^{2}=21,6 \%\right)$, com a Área Abaixo da Curva de Progresso da Doença (AUDPC) $\left(\mathrm{r}^{2}=25,4 \%\right)$ e com a Integral da Diferença Normalizada $\left(\mathrm{AUR}_{\mathrm{NDVI}}\right)\left(\mathrm{r}^{2}=54,8 \%\right)$. Verificou-se diferença significativa $(\mathrm{P}<0,05)$ na Eficiência Fotossintética (RUE) entre a testemunha e o tratamento que recebeu três aplicações de fungicida (primeira em $\mathrm{R}_{4}$ ), sendo esse também o único tratamento que diferiu significativamente $(\mathrm{P}<0,05)$ da testemunha em produtividade. Apesar dos baixos valores para os coeficientes de determinação, a sensibilidade das medidas de NDVI e RUE apresentaram potencial para captar variações entre os tratamentos. Sugerem-se novos estudos para verificar e eliminar possíveis interferências decorrentes da calibração do radiômetro e dos demais parâmetros antes dessas medidas poderem ser utilizadas no processo de tomada de decisão para controle da ferrugem asiática.

Palavras-chave: Radiômetro, Phakopsora pachyrhizi, Glycine max, sensoriamento remoto

\begin{abstract}
The aim of this research was to verify if some measures of reflectance could detect variations in the healthy leaf area which could be used as parameter to estimate damages in the production due to soybean rust, and to determine the influence of the disease on photosinthetic efficiency of plants under field conditions. The experiment was lead in the experimental area of Embrapa, in Londrina, PR. The experimental design was randomly blocks, with eight treatments (different fungicide application times) with four replications. The fungicide used was azoxistrobin + ciproconazole $(60+24 \mathrm{~g}$ i.a./ha $)+$ mineral oil
\end{abstract}

1 Doutoranda em Agronomia da Universidade Estadual de Londrina (UEL), Londrina- PR / Bolsista do Capes.

2 Professor da Universidade Estadual de Londrina / Departamento de Agronomia / Bolsista de Produtividade em Pesquisa CNPq. E-mail: canteri@uel.br

3 Pesquisadora da Embrapa Soja.

* Autor para correspondência 
$(0.5 \%)$. The reflectance readings were made at eight wave lengths, between 460 and $810 \mathrm{~nm}$, with intervals of $50 \mathrm{~nm}$. It was estimated the Normalized Difference Vegetation Index (NDVI), where NDVI=(810-660)/ $(810+660)$. The yield presented linear increments $(\mathrm{P}<0.01)$ with Healthy Leaf Area Duration (HAD) $\left(r^{2}=37.7 \%\right)$, with Healthy Area Absorption (HAA) $\left(r^{2}=21.6 \%\right)$, with Area Under Disease Progress Curve (AUDPC) $\left(r^{2}=25.4 \%\right)$ and with Integral of Normalized Difference $\left(A_{U N} R_{\mathrm{NDVI}}\right)\left(\mathrm{r}^{2}=54.8 \%\right)$. Significant difference in Photosynthetic Efficiency (RUE) $(\mathrm{P}<0.05)$ was observed between the control plot and the treatment with three fungicide applications (first at $\mathrm{R}_{4}$ ), which was the only treatment that differed significantly $(\mathrm{P}<0.05)$ in production from untreated control. The sensitivity of the measures NDVI and RUE presented a potential to detect variations among the treatments. However additional studies are still needed to verify and eliminate some possible interferences, such as the calibration of the radiometer and other parameters before it can be used for taking of decisions.

Key words: Radiometer, Phakopsora pachyrhiz, Glycine Max, remote sensing

\section{Introdução}

Atualmente uma das doenças em soja [Glycine $\max ($ L.) Merrill] de maior importância é a ferrugem asiática, causada por Phakopsora pachyrhizi Syd. \& P. Syd. O seu controle compreende diversas medidas conjuntas, contudo a maior parte das pesquisas tem como alvo o emprego de fungicidas e a resistência da planta hospedeira. Quando a doença já está ocorrendo, o controle químico com fungicida é, até o momento, o principal método de controle (YORINORI; WILFRIDO, 2002; EMPRESA BRASILEIRA DE PESQUISA AGROPECUÁRIA, 2004; SOARES et al., 2004).

Os danos provocados por doenças em plantas podem ser estimados por modelos obtidos da relação injúria-dano, descritos por Bergamin-Filho et al. (1997). Entretanto, esses modelos são baseados na lógica incerta da relação injúria-dano (WAGGONER; BERGER, 1987). Outras desvantagens apresentadas pela maioria dos modelos baseados nessa relação são a falta de transportabilidade (ROUSE, 1988) e o fato de serem destinados a apenas uma doença, situação rara de se observar no campo, onde podem ocorrer simultaneamente várias doenças em uma mesma planta.

Para estimar a redução da produção induzida por doenças, Waggoner e Berger (1987) propuseram o uso da duração da área foliar sadia (HAD - Duração da área foliar sadia) e da absorção da radiação solar pela área foliar sadia (HAA - Absorção da radiação solar pela área foliar sadia). Os autores relembram que o conceito de produção de uma planta é função da energia interceptada pelas folhas sadias durante o ciclo da cultura, dando maior consistência fisiológica às estimativas de danos.

Para viabilizar o uso de HAD e HAA no cálculo de danos, técnicas de sensoriamento remoto têm demonstrado potencial para execução de estimativas rápidas e precisas do índice da área foliar, principalmente sob condições de campo (CANTERI, 1998).

Os sensoriamentos in situ na agricultura, realizado através da utilização do radiômetro, envolvem a detecção da energia eletromagnética, tais como luz e calor, contidas/emitidas pelo objeto em estudo. Essa técnica pode ser aplicada como uma das ferramentas de suporte ao manejo e controle de doenças em plantas, uma vez que há diferenças nas respostas espectrais de uma planta sadia (maior refletância na banda do infravermelho) e uma planta doente (SILVA et al., 2000).

O objetivo do trabalho foi verificar se as medidas de refletância detectavam variações na área foliar sadia a fim de estimar danos na produção decorrentes da ferrugem asiática, bem como determinar a influência da doença na eficiência fotossintética das plantas em condições de campo.

\section{Material e Métodos}

\section{Delineamento experimental}

O experimento foi conduzido na área experimental pertencente à Embrapa Soja, no município de Londrina-PR, localizado a $23^{\circ} 18^{\prime} 37^{\prime \prime}$ de latitude Sul, 
5109'46" de longitude Oeste, $585 \mathrm{~m}$ de altitude. A pesquisa foi realizada durante a safra 2004/2005, com a semeadura da cultivar BRS 154 em 06/12/04, com colheita efetuada em 12/04/05. O delineamento experimental utilizado foi o de blocos ao acaso, com oito tratamentos e quatro repetições, sendo cada parcela constituída por seis linhas de $5,0 \mathrm{~m}$, espaçadas 0,45 m entre linhas. Considerou-se como área útil para a aplicação dos tratamentos e coleta de dados as quatro linhas centrais, e como bordaduras as duas linhas externas e $0,5 \mathrm{~m}$ das extremidades da parcela.

O produto utilizado foi azoxistrobin + ciproconazole $(60+24$ g i.a./ha) + óleo mineral (0,5\%) (EMPRESA BRASILEIRA DE PESQUISA AGROPECUÁRIA, 2005). Os tratamentos testados encontram-se na Tabela 1.

Tabela 1. Número e estádios das aplicações para controle da ferrugem asiática da soja.

\begin{tabular}{|c|c|c|}
\hline Tratamento & $\begin{array}{l}\text { Número de } \\
\text { Aplicaç̃es }\end{array}$ & $\begin{array}{l}\text { Estádio da } \\
\text { Aplicação }\end{array}$ \\
\hline T1 (Testemunha) & 0 & -- \\
\hline T2 (Controle) & 4 & $\mathrm{R}_{2}, \mathrm{R}_{4}, \mathrm{R}_{5.2}, \mathrm{R}_{5.5}$ \\
\hline $\mathrm{T} 3$ & 3 & $\mathrm{R}_{4}, \mathrm{R}_{5.2}, \mathrm{R}_{5.5}$ \\
\hline $\mathrm{T} 4$ & 3 & $\mathrm{R}_{5.1}, \mathrm{R}_{5.4}, \mathrm{R}_{6}$ \\
\hline T5 & 2 & $\mathrm{R}_{5.2}, \mathrm{R}_{5.5}$ \\
\hline T6 & 2 & $\mathrm{R}_{5.4}, \mathrm{R}_{6}$ \\
\hline $\mathrm{T} 7$ & 1 & $\mathrm{R}_{5.5}$ \\
\hline T8 & 1 & $\mathrm{R}_{6}$ \\
\hline
\end{tabular}

Sendo o tratamento T1, a testemunha sem aplicações, e o T2, o controle com aplicações quinzenais iniciadas em $\mathrm{R}_{2}$. Nos demais tratamentos, as aplicações iniciaram-se nos estádios fenológicos subsequientes realizando-se re-aplicações quinzenais até o estádio $\mathrm{R}_{6}$.

\section{Parâmetros Avaliados}

Os dados climáticos correspondentes aos períodos de experimentação foram obtidos junto à estação meteorológica pertencente ao Instituto Agronômico do Paraná (IAPAR), em função da sua proximidade com a área experimental.

A quantificação da severidade da doença, porção da área foliar com sintomas da ferrugem asiática da soja foi realizada com o auxílio da escala diagramática desenvolvida por Godoy, Koga e Canteri (2006). Foram selecionados quatro pontos aleatórios em cada uma das parcelas do ensaio, onde foram coletados trifólios do terço inferior, médio e superior (um trifólio de cada altura) das plantas, estimando-se dessa forma a severidade média, em porcentagem.

O índice da área foliar (LAI - Índice da Área Foliar) foi estimado pela média de quatro leituras realizadas com ceptômetro (LAI-2000 Plant Canopy Analyser - Li-Cor) em cada parcela. A relação entre a luz incidente em cima da cultura e embaixo da copa das plantas fornece a transmitância de cada ângulo, que é inversamente proporcional ao LAI (HOFFMAN; BLOMBERG, 2004).

O valor da área sob a curva de progresso da doença (AUDPC - Área Abaixo da Curva de Progresso da Doença) para cada parcela foi calculado por integração trapezoidal (SHANER; FINNEY, 1977):

$$
\mathrm{AUDPC}=\sum_{i=1}^{n-1}\left[\left(X_{i}+X_{i+1}\right) / 2\right]\left(t_{i+1}-t_{i}\right)
$$

onde $\mathrm{X}$ é a severidade média da doença por parcela (dada em proporção), $\mathrm{Xi}=\mathrm{X}(\mathrm{ti}), \mathrm{n}$ é o número de avaliações e (ti+1 - ti) é o intervalo entre duas avaliações consecutivas.

A duração da área foliar sadia (HAD) para cada parcela foi calculada pela fórmula: 


$$
\begin{gathered}
\mathrm{HAD}= \\
\sum_{i=1}^{n-1}\left\{\left[L A I_{i}\left(1-X_{i}\right)+L A I_{i+1}\left(1-X_{i+1}\right)\right] / 2\right\}\left(t_{i+1}-t_{i}\right)
\end{gathered}
$$

onde LAIi $=\mathrm{LAI}(t i), X$ é a severidade média da doença por parcela (dada em proporção), $X \mathrm{i}=X(t i)$, $n$ é o número de avaliações e $\left(t_{i+1}-t_{\mathrm{i}}\right)$ é o intervalo entre duas avaliações consecutivas.

O valor da absorção da área foliar sadia (HAA) em MJ.m-2 para cada parcela foi calculado como:

$$
\begin{gathered}
\mathrm{HAA}= \\
\sum_{i=1}^{n-1} I_{i}\left(\left\{\left(1-X_{i}\right)\left[1-\exp \left(-k L A I_{i}\right)\right]+\left(1-X_{i+1}\right) \mid\right.\right. \\
\left.\left.\left[1-\exp \left(-k L A I_{i+1}\right)\right]\right\} / 2\right)\left(t_{i+1}-t_{i}\right)
\end{gathered}
$$

onde $I i$ é a média de radiação solar incidente (MJ.m$\left.{ }^{2}\right)$ no período $(t i+l-t i), k$ é o coeficiente de extinção; utilizou-se $k=0,7$ (BERGAMIN FILHO et al., 1997), LAIi $=\mathrm{LAI}(t i), X$ é a severidade média da doença por parcela, $n$ é o número de avaliações e $\left(t_{i+1}-t_{\mathrm{i}}\right)$ é o intervalo entre duas avaliações consecutivas. A radiação solar incidente $(I)$ foi medida pelas estações meteorológicas do Instituto Agronômico do Paraná (IAPAR).

Calculou-se a eficiência do uso da radiação (RUE - Eficiência de Uso da Radiação, em g.MJ ${ }^{-1}$ ) para cada parcela pela divisão da produtividade $\left(\mathrm{g} \cdot \mathrm{m}^{-2}\right)$ pela HAA (MJ.m-2).

As medidas de refletância foram usadas para calcular o índice vegetativo da diferença normalizada $(\mathrm{NDVI})$, onde NDVI $=(\mathrm{IR}-\mathrm{R}) /(\mathrm{IR}+\mathrm{R})(\mathrm{NILSSON}$, 1995). Utilizou-se para os comprimentos de onda no infravermelho (IR - Infravermelho) os valores de 760 e 810 nanômetros (nm) e para o vermelho (R Vermelho) os comprimentos de onda 610 e $660 \mathrm{~nm}$. A banda do IR (760 a $900 \mathrm{~nm}$ ) corresponde ao pico de refletância da cultura da soja e a banda do R (630 a $690 \mathrm{~nm}$ ) corresponde ao pico da absortância na região do visível (TUCKER, 1979).
Para cada comprimento de onda e para os índices vegetativos, foram calculados por integração trapezoidal os valores da área sob a curva das medidas de refletância (AUR - Área Abaixo da Curva de Radiação) para cada parcela, pela fórmula:

$$
\mathrm{AUR}=\sum_{i=1}^{n-1}\left[\left(R i+R_{\mathrm{i}+1}\right) / 2\right]\left(\mathrm{t}_{\mathrm{i}+1}-\mathrm{t}_{\mathrm{i}}\right)
$$

onde $\mathrm{R}$ é a medida de refletância em cada comprimento de onda (porcentagem), Ri = R(ti), né o número de avaliações e (ti+1 - ti) é o intervalo entre duas avaliações consecutivas.

\section{Análise dos Dados}

Os dados foram submetidos à análise de variância, pelo teste de $\mathrm{F}$, e as diferenças entre as médias, quando significativas, foram comparadas pelos testes de Tukey, ao nível de 5\% de probabilidade, usandose o programa SASM-Agri (CANTERI et al., 2001). As relações entre produtividade e HAD e HAA, entre produtividade e medidas de refletância e entre medidas de refletância e HAD e HAA foram examinadas por regressão linear, utilizando-se o programa Excel. Para a análise dos resultados de HAD, HAA e refletância foram consideradas as 32 parcelas isoladamente.

\section{Resultados e Discussão}

As médias da temperatura média e da umidade relativa registradas foram de $23,9^{\circ} \mathrm{C}$ e $69,3 \%$ respectivamente. A precipitação acumulada no período de desenvolvimento do experimento (06/12/2004 a 12/ 04/2005) foi de 736,6 mm. Apesar da precipitação estar dentro da faixa para a obtenção de máximo rendimento da cultura da soja, que varia de 480 a $800 \mathrm{~mm} / \mathrm{ciclo}$, foi mal distribuída, sendo praticamente ausente no período de floração ao enchimento de grãos, média $1 \mathrm{~mm} / \mathrm{dia}$, período em que a cultura precisa de 7 a $8 \mathrm{~mm} / \mathrm{dia}$ (EMPRESA BRASILEIRA DE PESQUISA AGROPECUÁRIA, 2004). 
O fato de não terem ocorrido precipitações em quantidades suficientes a partir da floração inibiu tanto o desenvolvimento da cultura quanto o progresso da ferrugem asiática na safra 2004/05. Estudos conduzidos na Tailândia por Kawuki, Adipala e Tukamuhabwa (2003) demonstraram que em estações secas ocorreram reduções de 10-15\% na produção comparadas com perdas de $100 \%$ ocorridas durante estações chuvosas decorrentes da $P$. pachyrhizi.

Os primeiros sintomas da ferrugem asiática da soja foram observados aos 56 dias após a emergência (DAE), no estádio $\mathrm{R}_{4}$. De acordo com a metodologia adotada, a epidemia foi considerada de baixa a mediana, apresentando nível máximo de severidade na testemunha de $13,2 \%$, até o estádio $\mathrm{R}_{6}$.

As avaliações de severidade foram realizadas até o estádio $R_{7.1}$, contudo neste período as folhas das parcelas já se encontravam secas e encarquilhadas em função da estiagem que adiantou o desenvolvimento da cultura. O que impossibilitou a continuidade das avaliações de severidade até o estádio da maturação fisiológica da soja $\left(\mathrm{R}_{9}\right)$.

$\mathrm{Na}$ relação de HAD e HAA com os comprimentos de onda (Tabela 2) verificou-se que os valores de $r^{2}$ para a regressão linear, isto é, a porcentagem de variação total explicada pelos modelos foi baixa. Um possível motivo para este fato foi o estresse hídrico que limitou o desenvolvimento da doença e da própria cultura e influenciou o ajuste do modelo na estimação dos parâmetros.

Contudo a relação de HAD e HAA com a área abaixo da curva da radiação (AUR) dos dois comprimentos de onda do R, do IR e dos índices vegetativos de diferença normalizada (NDVI) apresentados na Tabela 2 foi significativa $(\mathrm{P}<0,01)$. Isto é, os valores de $\mathrm{P}$ demonstraram que houve alta relação entre os valores de refletância com HAD e HAA, com um grau de confiança superior a 99\% de probabilidade (BONZATTO; KRONKA, 1995).

Tabela 2. Coeficiente de determinação $\left(\mathrm{r}^{2}\right)$, nível de significância da análise de variância da regressão linear (P-valor) e coeficiente angular (b) para as relações entre HAD e HAA com AUR de 610, 660, 760 e 810 nm, e NDVI (760/610), (760/ 660), (810/610) e (810/660), durante a safra agrícola 2004/2005.

\begin{tabular}{|c|c|c|c|c|c|c|}
\hline \multirow[t]{2}{*}{ Refletância } & \multicolumn{3}{|c|}{ HAD } & \multicolumn{3}{|c|}{ HAA } \\
\hline & $\mathrm{b}$ & P - Valor* & $r^{2}$ & $\mathrm{~b}$ & $\mathrm{P}-$ Valor* & $\mathrm{r}^{2}$ \\
\hline AUR $_{610}$ & 0,144 & $\mathrm{P}<6,7 \times 10^{-5}$ & 37,6 & 0,202 & $\mathrm{P}<0,0004$ & 31,0 \\
\hline AUR 660 & $-1,923$ & $\mathrm{P}<0,0001$ & 36,2 & $-2,898$ & $\mathrm{P}<0,0007$ & 28,8 \\
\hline AUR 760 & 0,096 & $\mathrm{P}<7,3 \times 10^{-5}$ & 37,5 & 0,132 & $\mathrm{P}<0,0006$ & 29,8 \\
\hline AUR $_{810}$ & 0,094 & $\mathrm{P}<5,7 \times 10^{-5}$ & 38,3 & 0,130 & $\mathrm{P}<0,0004$ & 31,0 \\
\hline NDVI $_{760 / 610}$ & 15,904 & $\mathrm{P}<0,0082$ & 18,8 & 29,636 & $\mathrm{P}<0,0010$ & 27,4 \\
\hline NDVI $_{760 / 660}$ & 15,329 & $\mathrm{P}<5,0 \times 10^{-5}$ & 38,8 & 22,637 & $\mathrm{P}<0,0001$ & 35,5 \\
\hline NDVI $_{810 / 610}$ & 23,723 & $\mathrm{P}<0,0009$ & 27,9 & 39,266 & $\mathrm{P}<0,0003$ & 32,1 \\
\hline NDVI $_{810 / 660}$ & 19,786 & $\mathrm{P}<7,9 \times 10^{-8}$ & 57,7 & 23,749 & $\mathrm{P}<0,0002$ & 34,9 \\
\hline
\end{tabular}

* Valores de $\mathrm{P}<0,01$ indicam regressão significativa a $1 \%$.

A produtividade $\left(\mathrm{g} . \mathrm{m}^{-2}\right)$ apresentou incremento linear $(\mathrm{P}<0,01)$ com o incremento da HAD e da HAA, confirmando a possibilidade de uso destas variáveis para estimar os danos provocados pela ferrugem asiática. A equação para relação produçãoHAD foi: produção = 20,7 + 0,9 HAD $\left(\mathrm{r}^{2}=37,7 \%\right)$, e para HAA foi: produção $=204,5+0,5$ HAA $\left(r^{2}=\right.$ $21,6 \%)$. Os coeficientes de determinação $\left(r^{2}\right)$ encontrados foram baixos quando comparados àqueles observados por Godoy (1995); BergaminFilho et al. (1997) e Canteri (1998), que desenvolveram trabalhos similares com feijoeiro.

Vários trabalhos indicam que o HAA fornece uma melhor relação com a produção em comparação ao HAD (BRYSON et al., 1997; BERGAMIN FILHO et al., 1997; CANTERI, 1998), o que não ocorreu 
no presente ensaio. Uma possível hipótese para o $\mathrm{r}^{2}$ ter sido maior para HAD que para HAA seria que a radiação incidente absorvida demonstrada nos resultados dos cálculos não foi eficientemente utilizada em decorrência da falta de água para realização da fotossíntese. Para ter certeza do ocorrido seria necessário ter se realizado medições diretas das taxas de fotossíntese (VAN OIJEN, 1990), que não foi realizado no presente estudo.

A HAD apresenta desvantagem similar a AUDPC, pois não leva em consideração o tamanho das folhas e nem a diminuição do efeito do aumento do tamanho do dossel na proporção de radiação interceptada. Isto influencia a adoção das estratégias de controle de doenças, pois folhas maiores podem ser capazes de tolerar alguma perda da sua área verde fotossintetizante sem uma queda significativa na produtividade (BRYSON et al., 1997).

A relação entre produção e medidas de refletância foi significativa $(\mathrm{P}<0,05)$ para a integral da refletância em $810 \mathrm{~nm}\left(\mathrm{AUR}_{810}\right) \operatorname{com~} \mathrm{r}^{2}=13,5 \%$, e $(\mathrm{P}<0,01)$ para a integral da diferença normalizada $\left(\mathrm{AUR}_{\mathrm{NDVI}}\right)$ com $\mathrm{r}^{2}=54,8 \%$, valores estes bem menores que os encontrados para o patossistema Cercosporidium personatum-Sphacelloma arachidis / amendoim $\left(\right.$ AUR $_{810}$ com r $\left.^{2}=84,5\right)($ CANTERI et al., 1999) e Septoria tritici / trigo $\left(\mathrm{AUR}_{\mathrm{NDVI}}\right.$ com $\mathrm{r}^{2}=92,7 \%$ ) (NICOLAS, 2004). Os índices de AUR $\mathrm{NDVI}_{\mathrm{N}}$ mostraramse mais eficiente em correlações com a produção do que o valor de refletância no infravermelho próximo utilizado isoladamente $\left(\mathrm{AUR}_{810}\right)$. Outros autores já haviam sugerido o uso da diferença normalizada por apresentar melhores relações com a produção (ASRAR et al., 1984; NILSSON, 1995). No presente trabalho, o comprimento de onda na faixa do vermelho que forneceu melhores resultados na equação da NDVI foi $660 \mathrm{~nm}$.

Os baixos valores de $\mathrm{r}^{2}$ encontrados para as relações com produção têm três explicações: i) o estresse hídrico que atingiu a cultura em estádios críticos; ii) a pouca amplitude dos valores de produtividade; e iii) a pouca amplitude dos valores da doença. A falta de precipitação nos estádios cruciais para do desenvolvimento da cultura pode ser observada na baixa média de produtividade dos tratamentos (Tabela 3). A produtividade variou entre 134,5 a 223,4 g.m-2 , e os baixos níveis de severidade (máximo de 13,2\% em $\mathrm{R}_{6}$ ).

Os tratamentos foram definidos buscando obter diferentes níveis de severidade da ferrugem asiática e, consequentemente, variações na área foliar e na produção. Entretanto, não houve diferenças significativas entre os tratamentos para absorção da área foliar sadia (HAA), nem para a integral das medidas de refletância em $810 \mathrm{~nm}\left(\mathrm{AUR}_{810}\right)$, pelo teste de Tukey $(\mathrm{P}<0,05)$ (Tabela 3). O coeficiente de variação observado para a análise de variância das variáveis HAA e AUR $_{810}$ foi baixo, 2,4\% e 4,5\% respectivamente, demonstrando alta precisão para o experimento (GOMES, 1987). A ausência de diferenças significativas para estas variáveis pode ser explicada pelo pouco efeito da quantidade de doença sobre a área foliar neste ensaio.

Em relação à doença, representada pela AUDPC, a maior porcentagem de controle (PC) foi observada para o tratamento $2(80,2 \%)$, com quatro aplicações. Entretanto, mesmo os tratamentos que receberam três ou duas aplicações (T3, T4, T5 e T6) não diferiram estatisticamente do tratamento $2 \mathrm{O}$ tratamento 8 foi o que apresentou menor eficiência de controle $(12,0 \%)$, com uma aplicação feita em $\mathrm{R}_{6}$. Quanto mais avançado o estádio em que se iniciaram as aplicações, menor foi a PC da ferrugem asiática da soja.

Os resultados do presente experimento, sob as condições em que foi conduzido indicaram que quando se realizaram duas aplicações, sendo a primeira em $\mathrm{R}_{5.2}$, com severidade de $3,0 \%$, obtevese controle da ferrugem estatisticamente semelhante ao observado com quatro aplicações. Entretanto, o tratamento com quatro aplicações, que recebeu pulverização na floração plena, apresentou produtividade menor do que o esperado. Três aplicações incrementaram a produtividade, quando iniciadas em $\mathrm{R}_{4}$. 
Tabela 3. Absorção de área foliar sadia (HAA), área sob a curva de progresso da doença (AUDPC), eficiência fotossintética (RUE), produção e medidas de refletância observadas para tratamentos com diferentes épocas de início das pulverizações para controle da ferrugem asiática.

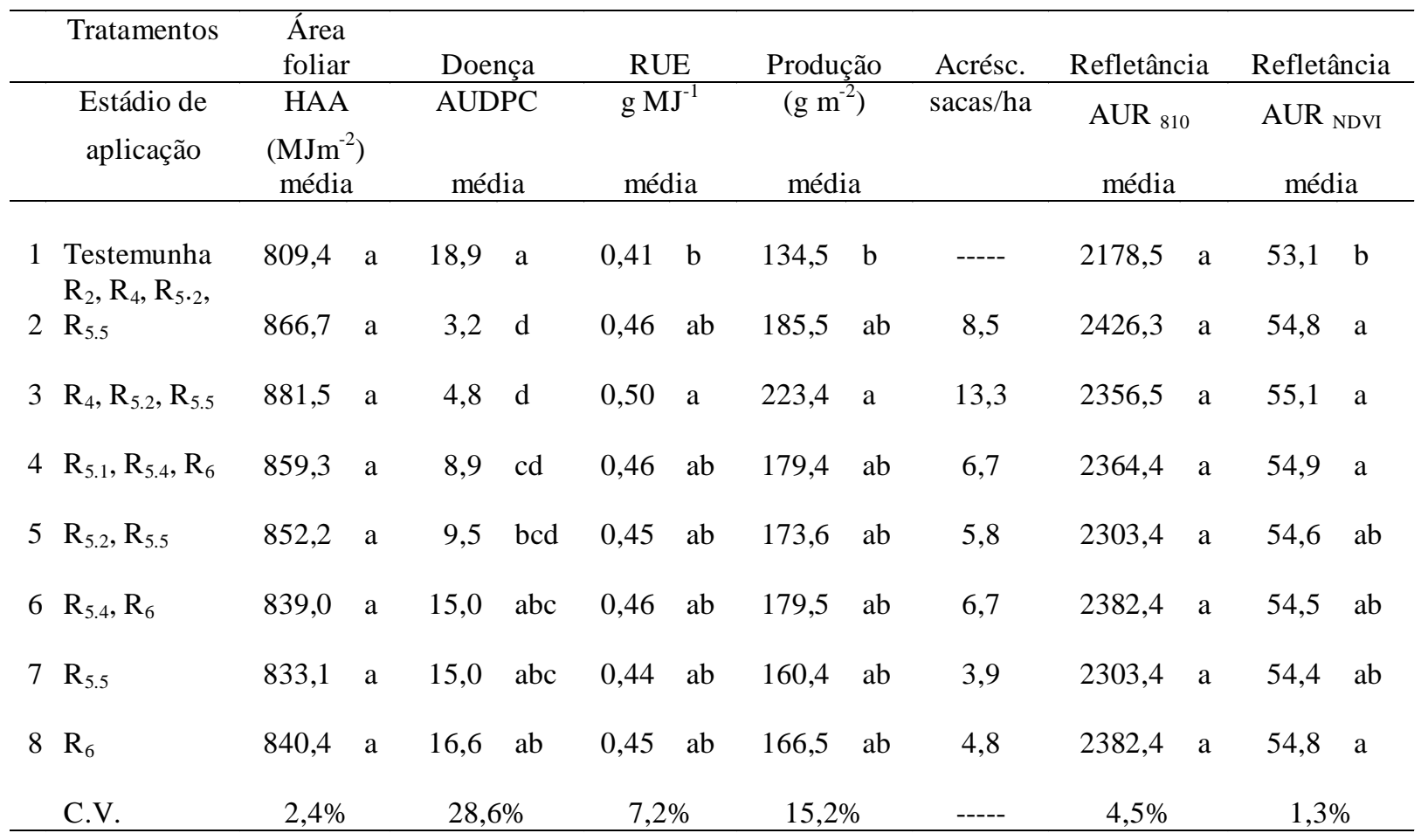

Médias seguidas de mesma letra não diferem estatisticamente entre si pelo teste de Tukey $(\mathrm{P}<0,05)$

A produtividade apresentou diferença significativa $(\mathrm{P}<0,05)$ apenas entre os tratamentos 1 (Testemunha) e 3 (3 aplicações). Esta diferença esteve relacionada com a variação de HAA e da intensidade da ferrugem asiática. A integral do índice vegetativo da diferença normalizada $\left(\mathrm{AUR}_{\mathrm{NDVI}}\right)$ apresentou um comportamento estatisticamente semelhante à produtividade $\left(\mathrm{g} \cdot \mathrm{m}^{-2}\right)$ e a eficiência de uso da radiação (RUE), indicando maior relação com estas variáveis do que com a AUDPC.

Apesar dos demais tratamentos (T2, T4, T5, T6, T7 e T8) não terem diferido significativamente da testemunha, obteve-se um acréscimo no número de sacas por hectare em relação a testemunha, respectivamente de 8,$5 ; 6,7 ; 5,8 ; 6,7 ; 3,9$ e 4,8 .

Para analisar a interferência na eficiência fotossintética provocada pela ferrugem asiática, calculou-se a eficiência do uso da radiação (RUE) para produtividade de grãos, em g.MJ ${ }^{-1}$, para os 8 tratamentos. A estimativa da RUE foi feita dividindose a produtividade $\left(\mathrm{g} . \mathrm{m}^{-2}\right)$ pela HAA $\left(\mathrm{MJ} . \mathrm{m}^{-2}\right)$ (CANTERI, 1998) (Tabela 3).

A maior RUE foi observada para o tratamento 3 $\left(0,50\right.$ g. $\left.\mathrm{MJ}^{-1}\right)$ e a menor RUE para o tratamento 1 $\left(0,41\right.$ g. $\left.\mathrm{MJ}^{-1}\right)$. Verificou-se diferença significativa $(\mathrm{P}<0,05)$ entre esses dois tratamentos. Apesar dos tratamentos 2 ter recebido 4 aplicações, este não apresentou a maior RUE, provavelmente em função de terem recebido a primeira pulverização na floração plena, o que pode ter afetado negativamente na produtividade final.

No presente ensaio, a variação significativa $(\mathrm{P}<0,05)$ para RUE, talvez se deva aos altos valores encontrados de área foliar sadia (HLAI - Índice de Área Foliar Sadia), superiores a cinco. Em condições de campo, Bergamin Filho et al. (1997), também verificaram grande variação na RUE para ensaios com HLAI máximo próximo a cinco para feijão. 
Apesar das evidências, somente medições diretas das taxas de fotossíntese de plantas sadias e doentes podem mostrar se realmente há variação na RUE (VAN OIJEN, 1990).

Qualquer modelo, para que tenha aplicação, deve ser validado com dados diferentes daquele que o originou antes de ser feita sua validação (KRANZ; ROYLE, 1978). Sugere-se que novos trabalhos sejam desenvolvidos com o objetivo de validar os modelos obtidos neste ensaio, e também para verificar e eliminar possíveis interferências decorrentes da calibração do radiômetro.

\section{Conclusões}

Houve relação significativa entre os valores de refletância com a duração da área foliar sadia (HAD) e com a absorção da radiação solar pela área foliar sadia (HAA).

As melhores relações com a HAD e com a HAA foram obtidas com o índice vegetativo de diferença normalizada (NDVI), que usou os comprimentos de onda 810 e $660 \mathrm{~nm}$ e 760 e $660 \mathrm{~nm}$, respectivamente.

Houve efeito da ferrugem asiática da soja na eficiência fotossintética (RUE) das plantas no campo.

A sensibilidade nas medidas de NDVI e RUE apresentou potencial para captar variações entre os tratamentos.

\section{Agradecimentos}

Ao Departamento de Agronomia da Universidade Estadual de Londrina por todo o apoio, à Capes pelo apoio financeiro, à Embrapa Soja Londrina por ter cedido à área experimental e por ter viabilizado a utilização do ceptômetro e ao Instituto Agronômico do Paraná por ter fornecido os dados climático e viabilizado a utilização do radiômetro.

\section{Referências}

ASRAR, G.; FUCHS, M.; KANEMASU, E. T.; HATFIELD, J. L. Estimating absorbed photosynthetic radiation and leaf area index from spectral reflectance in wheat. Agronomy Journal, Madison, v.76, p.300-306, 1984.

BERGAMINFILHO, A.; CARNEIRO, S.M.T.P.G.;GODOY, C. V.; AMORIM, L.; BERGER, R. D.; HAU, B. Angular leaf spot of phaseolus beans: relationships between disease, healthy leaf area, and yield. Phytopathology, Saint Paul, v.87, p.506-515, 1997.

BONZATTO, D. A.; KRONKA, S. N. Experimentação agrícola. 3.ed. Jaboticabal: FUNEP, 1995.

BRYSON, R. J.; PAVELEY, N. D.; CLARK, W. S.; SYLVESTER-BRADLEY, R.; SCOTT, R. K. Use of in-field measurements of green leaf area and incident radiation to estimate the effects of yellow rust epidemics on the yield of winter wheat. European Journal of Agronomy, Amsterdam, v.7, p.53-62, 1997.

CANTERI, M. G. Uso de medidas da área foliar sadia e refletância no manejo da mancha angular do feijoeiro. 1998. Tese (Doutorado em Agronomia) - Escola Superior de Agricultura "Luiz de Queiroz", Universidade de São Paulo, Piracicaba.

CANTERI, M. G.; AGNELO, J. V.; AMORIM, L.; BERGAMIN FILHO, A. Refletância e avaliação visual como indicadores de severidade de doenças foliares comparados à produtividade em amendoim. Summa Phytopathologica, Jaguariúna, v.25, p.228-233, 1999.

CANTERI, M. G.; ALTHAUS, R. A.; VIRGENS FILHO, J. S.; GIGLIOTI, E. A.; GODOY, C. V. SASM - Agri: Sistema para análise e separação de médias em experimentos agrícolas pelos métodos Scott - Knott, Tukey e Duncan. Revista Brasileira de Agrocomputação, Ponta Grossa, v.1, n.2, p.18-24, 2001.

EMPRESA BRASILEIRA DE PESQUISA AGROPECUÁRIA - EMBRAPA. Tecnologias de produção de soja: região central do Brasil 2005. Londrina: Embrapa Soja, 2004.

EMPRESA BRASILEIRA DE PESQUISA AGROPECUÁRIA - EMBRAPA. Tecnologias de produção de soja: região central do Brasil 2006. Londrina: Embrapa Soja, 2005.

GODOY, C. V. Danos causados pela mancha angular em feijoeiro, no município de Piracicaba. 1995. Dissertação. (Mestrado em Agronomia) - Escola Superior de Agricultura “Luiz de Queiroz", Universidade de São Paulo, Piracicaba. 
GODOY,C. V.; KOGA, L. J.; CANTERI, M. G. Diagrammatic scale for assessment of soybean rust severity. Fitopatologia Brasileira, Brasília, v.31, p.63-68, 2006.

GOMES, F. P. Curso de estatística experimental. 2.ed. Piracicaba: Nobel, 1987.

HOFFMANN, C. M.; BLOMBERG, M. Estimation of leaf area index of beta vulgaris $\mathrm{L}$. based on optical remote sensing data. Journal of Agronomy \& Crop Science, Berlin, v.190, p.197-204, 2004.

KAWUKI, R. S.; ADIPALA, E.; TUKAMUHABWA, P. Yield loss associated with soya bean rust (Phakopsora pachyrhizi Syd.) in Uganda. Journal of. Phytopathology, Berlin, v.151, p.7-12, 2003.

KRANZ, J.; ROYLE, J. Perspectives in mathematical modeling of plant disease epidemics. In: SCOTT, P. R.; BAINBRIDGE, A. (Ed.) Plant disease epidemiology. Oxford: Blackwell, 1978. p.111-119.

NICOLAS, H. Using remote sensing to determine of the date of a fungicide application on winter wheat. Crop Protection, Guildford, v.23, p.853-863, set. 2004.

NILSSON, H. E. Remote sensing and image analysis in plant pathology. Annual Review of Phytopathology, Palo Alto, v.33, p.489-527, 1995.

ROUSE, D. I. Use of crop growth-models to predict the effects of disease. Annual Review of Phytopathology, Palo Alto, v.26, p.183-201, 1988.
SHANER, G.; FINNEY, R. E. The effects of nitrogen fertilization on the expression of slow-mildwing in knox wheat. Phytopathology, Saint Paul, v.67, p.1051-1055, 1977.

SILVA, E. A.; SILVA, J. F. V.; MONICO, J. F. G.; HIROMOTO, D. M. Perspectivas no manejo e controle localizado de doenças das culturas: uma abordagem no manejo do nematóide de cisto da soja. In: BORÉM, A. Agricultura de precisão, Viçosa: Universidade Federal de Viçosa, 2000. p.409-453.

SOARES, R. M.; RUBIN, S. A. L.; WIELEWICKI, A. P.; OZELAME, J. G. Fungicidas no controle da ferrugem asiática (Phakopsora pachyrhizi) e produtividade da soja. Ciência Rural, Santa Maria, v.34, n.4, p.1245-1247, 2004.

TUCKER, C. J. Red e photographic infrared linear combination for monitoring vegetation. Remote sensing of environment, New York, v.8, p.127-150, 1979.

VAN OIJEN, M. Photosynthesis is not impaired in healthy tissue of blighted potato plants. Netherlands Journal of Plant Pathology, Wageningen, v.96, p.55-63, 1990.

YORINORI, J. T.; WILFRIDO, M. P. Ferrugem da soja: Phakopsora pachyrhizi Sydow. Londrina: Embrapa, 2002. (Folder).

WAGGONER, P. E.; BERGER, R. D. Defoliation, disease and growth. Phytopathology, Saint Paul, v.77, p.393-398, 1987. 
